\title{
The role of oxygen in metabolic regulation
}

\author{
Augustus T. Miller, Jr. \\ Department of Physiology, School of Medicine, \\ University of North Carolina, Chapel Hill, U.S.A.
}

\begin{abstract}
KURZFASSUNG: Die Rolle des Sauerstoffs bei der Stoffwechselregulation. Sauerstoff ist unter normalen Verhältnissen in relativem Uberfluß in den Zellen vorhanden und spielt bei der Regulation des Zellstoffwechsels daher keine direkte Rolle. Demgegenïber wird bei schwerer Hypoxie infolge des Sauerstoffmangels der Zellstoffwechsel verändert; in diesem Zustand wird der Sauerstoff zu einem bedeutenden Faktor bei der Regulation des Zellstoffwechsels. Die wichtigsten Probleme, welche geklärt werden müssen, sind: (1) die quantitative Bestimmung des Grades der zellulären Hypoxie, (2) die alkuten Reaktionen, welche infolge der zellulären Hypoxie auftreten und (3) die adaptiven Anderungen, welche während chronischer Hypoxie stattfinden. Die Kenntnisse, über die wir bezüglich dieser Probleme zur Zeit verfügen, werden analysiert und diskutiert.
\end{abstract}

\section{INTRODUCTION}

We are all familiar with the regulation of the energy metabolism of cells by the ADP-feedback system. Other factors which are essential, e. g. inorganic phosphate, substrate and oxygen, are less directly involved in regulation because they are usually present in excess. The studies of CHANCE \& WILLIAMs (1956) have shown, however, that each of these factors may limit the rate of respiration of isolated mitochondria. When oxygen is not present in adequate amounts in cells, it may become rate-limiting with a resulting alteration in the pattern of metabolism. A deficiency in the supply of oxygen also evokes complex adjustments, which tend to minimize the effects of the deficiency. It is the purpose of this paper to examine some of the metabolic consequences of hypoxia and, specifically, to seek an answer to the following three questions: What is hypoxia? How does hypoxia affect the functions of cells? What adaptive changes occur in chronic hypoxia?

A precise definition of hypoxia is difficult. The term has often been used to describe causes rather than effects; thus, a decrease in arterial oxygen tension is not necessarily an indication of oxygen lack in the cells because it may be compensated by increased blood flow, yet it is commonly referred to as hypoxia. A more acceptable definition of hypoxia is that it is the condition which exists when the supply of oxygen to the interior of living cells is reduced to a rate insufficient for their current metabolic needs, with the result that various cellular oxidation - reduction systems must shift toward a more reduced state (HUCKABEE 1958a). 
In order to determine whether intracellular oxygen tension is adequate, it is necessary to know (a) what the tension is, and (b) what tension is necessary for normal metabolism. Early quantitative data bearing on these questions were obtained by WINZLER (1941) in his studies on the respiration of suspensions of yeast cells. The critical $\mathrm{pO}_{2}$ of the medium (the oxygen tension at which the oxygen uptake by the cells begins to decline) was about $2 \mathrm{~mm} \mathrm{Hg}$, and the $\mathrm{Kmo}$ (the oxygen concentration at which respiration is reduced to one-half the maximal rate) was equivalent to a $\mathrm{pO}_{2}$ of about $0.5 \mathrm{~mm}$ $\mathrm{Hg}$. At body temperature the rate of oxygen uptake by isolated liver mitochondria begins to decline when the oxygen concentration of the medium falls below about $3 \mu \mathrm{M}$ (equivalent to a $\mathrm{pO}_{2}$ of about $1.8 \mathrm{~mm} \mathrm{Hg}$ ) (Jöbsis 1964). The critical $\mathrm{pO}_{2}$ of isolated liver cells in vitro is about the same (LONGMuir 1964), which suggests that the cell membrane offers no appreciable barrier to the diffusion of oxygen.

The uncertainties involved in the extrapolation of in vitro data to in vivo situations has stimulated attempts to relate oxygen consumption to intracellular oxygen tension in the intact organism. The crux of the problem is the determination of intracellular oxygen tension. The most direct approach would be the use of oxygen electrodes inserted into the cells, but the relatively large size of the available electrodes and the resultant tissue damage has made it difficult to obtain valid measurements. Recently, however, oxygen electrodes having tips 1 micron or less in diameter (CATER \& SILvER 1961) have been used to measure the oxygen tension of specific morphologic regions of the brain. Simultaneous recording of electrical activity makes it possible to determine when the oxygen electrode tip is just touching the membrane of a neuron (SrLver 1965) and hence is measuring an oxygen tension virtually that of the interior of the cell. The electrodes may also be chronically implanted, permitting the repeated measurement of brain oxygen tension in unanesthetized animals; it has been shown in this manner that brain oxygen tension is not significantly affected by the anesthetic used in the acute experiments. Measurements made with the aid of these microelectrodes emphasize the futility of attempting to determine a "tissue" oxygen tension. The tension measured by the electrode as it is moved slowly into the brain reflects not only the differences between gray and white matter, but also the proximity of the electrode to the nearest blood vessel. However, when the electrodes are accurately positioned with a stereotaxic apparatus, very reproducible results can be obtained from one animal to the next, and changes in blood flow and in blood oxygen tension can be shown to be the main determinants of the oxygen tension measured by the electrodes.

Another approach to the estimation of intracellular oxygen tension has been developed by Chance and his associates (Chance, Schoener \& Schindler 1964). This technique utilizes reflectance spectrophotometry for the simultaneous measurement of the degree of oxygenation of hemoglobin in the small vessels and of the fluorescence of mitochondrial $\mathrm{NADH}_{2}$ in the superficial zone of exposed organs with intact blood supply. The fluorescence emission of $\mathrm{NADH}_{2}$ is excited in the region of its broad UV absorption band ( 320 to $380 \mathrm{~m} \mu$ ), and the fuorescence yield is relatively high. The emission bands are in the region 440 to $480 \mathrm{~m} \mu$. At neither of these wave-length regions is there appreciable absorbancy change associated with oxygenation or deoxygenation of hemoglobin. In the combined method the deoxygenation of hemoglobin is measured spectroscopically at wave-lengths 600 and $543 \mathrm{~m} \mu$. 


\section{THE MECHANISM OF HYPOXIA}

In studies on the exposed brain of the rat, the physiological status of the organ was also monitored in terms of its electrical activity (EEG) and of the maintenance or cessation of breathing. When the oxygen concentration of the inspired air was lowered gradually, the deoxygenation of hemoglobin was already apparent at an inspired oxygen concentration of 15 per cent, but not until it had dropped below 5 per cent was

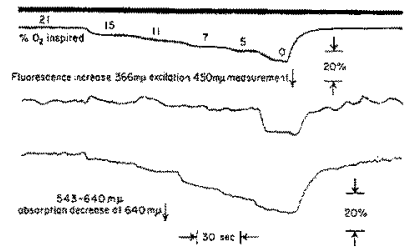

Fig. 1: Correlation between hemoglobin deoxygenation (bottom trace), fluorescence increase (middle trace) and per cent oxygen in the inspired air (top trace). (From Chance, Schoener \& Schindeler 1964, by permission of the authors and of the MacMillan Company)

there an appreciable increase in the reduction of NAD, and it then occurred very rapidly (Fig. 1). Cessation of the electrical activity of the brain and of breathing occurred only when the reduction of NAD (from the steady-state level) was about 90 per cent complete in animals in which the brain level of high energy phosphate compounds had previously been depleted by hypoxia or by drug-stimulation. When the energy reserves of the brain were normal, electrical activity continued for a few seconds after complete reduction of NAD, indicating the continued utilization of high energy compound reserves. The blood oxygen tension at which the critical level of NAD reduction ( 90 per cent in animals with depletion of high energy compounds) occurred was less than $4 \mathrm{~mm}$ $\mathrm{Hg}$; it is thus apparent that the degree of deoxygenation of hemoglobin is not a sensitive indicator of the intracellular oxidation-reduction state. Calibrations of the oxygen affinity for mitochondrial $\mathrm{NADH}_{2}$ show that the critical level of $\mathrm{NAD}$ reduction may actually require a fall of intracellular oxygen tension to about $0.04 \mathrm{~mm} \mathrm{Hg}$. When the oxygen tension of the blood in the small vessels, in CHANCE's experiments, was $12 \mathrm{~mm}$ $\mathrm{Hg}$, there was a reduction of NAD from the steady-state level of only about 50 per cent, and the EEG and breathing were normal. At this point intracellular oxygen tension (calculated) was about $0.1 \mathrm{~mm} \mathrm{Hg}$. It is thus apparent that very low intracellular oxygen tension is compatible with normal cell function. Hypoxia may be said to exist when the intracellular oxygen tension falls to a level at which the ratio of NAD to $\mathrm{NADH}_{2}$ begins to deviate from the usual steady-state value.

Under ordinary conditions of adequate oxygen supply anaerobic glycolysis is suppressed (PASTEUR effect), but it may supplement aerobic metabolism when the oxygen supply is inadequate. The basic reaction is:

$$
\text { Pyruvate }+\mathrm{NADH}_{2} \stackrel{\mathrm{LDH}}{\rightleftharpoons} \text { Lactate + NAD }
$$

(It is not implied of course that this is an energy-conserving step, but only that it is the essential reaction which permits the energy-conserving steps to continue under anaero- 
bic conditions.) In order to estimate the degree to which this reaction supplements aerobic metabolism in hypoxic cells, it was long considered adequate simply to measure the rate of production of lactic acid. Ir is now known, however, that the concentration of lactate is not always a valid index of anaerobic glycolysis, since it can be affected by factors other than oxygen lack. If the above reaction is rewritten in the mass action form and the terms transposed to give:

$$
[\text { Lactate }]=[\text { Pyruvate }] \times \mathrm{K} \frac{\left[\mathrm{NADH}_{2}\right]}{[\mathrm{NAD}]}
$$

it is at once apparent that [Lactate] can be influenced by changes in [Pyruvate] or in $\frac{\left[\mathrm{NADH}_{2}\right]}{[\mathrm{NAD}]}$ or both. However, only the increase in lactate concentration due to change in the ratio $\mathrm{NADH}_{2}: \mathrm{NAD}$ can be attributed solely to hypoxia. Pyruvate concentration is increased in hypoxia, but it is also increased in conditions having no relation to hypoxia (e.g. the infusion of glucose or pyruvate, and hyperventilation) (Fig. 2). The factors which determine the pyruvate levels in the body are complex, and their analysis is beyond the scope of this paper. HuckabeE (1958a) has proposed the term "excess lactate" to denote the increase in lactate due solely to hypoxia. Both lactate and pyruvate are measured, and the expected lactate concentration is also calculated from equation (2), on the assumption that the ratio of $\mathrm{NAD}$ to $\mathrm{NADH}_{2}$ remained unchanged. The

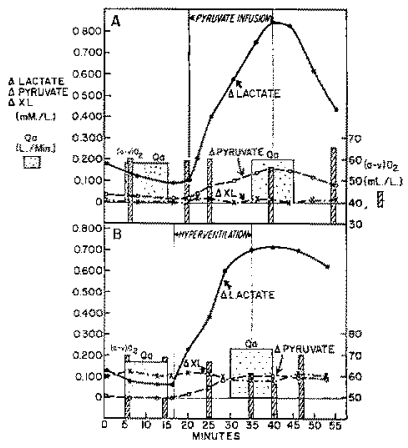

Fig. 2: Increase in blood lactate with no change in "excess lactate" following pyruvate infusion (A) and hyperventilation (B). (From Huck ABEe 1958a, by permission of the author and the Journal of Clinical Investigation)

amount by which the measured lactate concentration exceeds the calculated concentration must then have been due to change in the NAD : NADH 2 ratio, and hence to hypoxia, and is therefore the "excess lactate" (abbreviated XL). Equation (2) may be rewritten in the form:

$$
\mathrm{XL}=(\mathrm{Ln}-\mathrm{Lo})-(\mathrm{Pn}-\mathrm{Po})(\mathrm{Lo} / \mathrm{Po})
$$

where Lo and Po are the lactate and pyruvate concentrations at zero time, and Ln and $\mathrm{Pn}$ are the lactate and pyruvate values at time $\mathrm{n}$. XL then represents the lactate increase due to hypoxia alone. Measured values of lactate and pyruvate in arterial (but not local venous) blood permit the calculation of excess lactate in the tissues of the whole body 
(assuming complete equilibrium of distribution), and thus serve as an indication of the adequacy of tissue oxygen supply. Using this approach, Huckabee (1958b) observed that the breathing of low oxygen mixtures was associated with an elevation in blood lactate, but not of excess lactate, when the inspired oxygen concentration was reduced to 13 per cent (Fig. 3). Further reduction of inspired oxygen concentration to 10 per
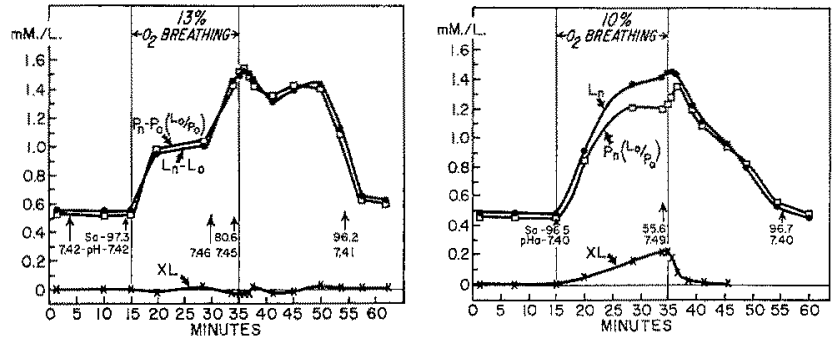

Fig. 3: Changes in total lactate and excess lactate concentrations in the blood during the breathing of low oxygen gas mixtures. (From HuckabeE 1958b, by permission of the author and the Journal of Clinical Investigation)

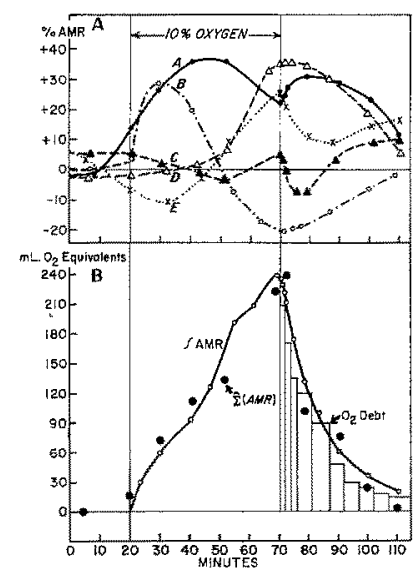

Fig. 4: A - Relative rates of anaerobic metabolism of all body tissues of a dog divided into five local regions, during mild respiratory hypoxia. B - Line AMR is the curve of accumulation of total body excress lactate with time in the same experiment shown in A. Points $\Sigma$ (AMR) are values obtained by summation of all local AMR's shown in part A and approximate the measured values (line AMR) fairly well. (From HuCKABEE 1959, by permission of the author and the American Journal of Physiology)

cent was associated with a small but significant increase in excess lactate, indicating increased anaerobic metabolism and the presumed existence of some degree of hypoxia. (Note that this is apparently not in agreement with the work of CHANCE, which indicates that inspired oxygen concentration must fall below 5 per cent before there is intracellular hypoxia in brain.) The transition point of about 10 per cent oxygen in the inspired air is equivalent to an altitude of about 18,000 feet. The implication is that up to this altitude, because of cardiovascular and respiratory adjustments, there is no true 
hypoxia (or at least no increase in anaerobic metabolism). This concept is supported, furthermore, by the fact that the oxygen consumption of the whole organism is usually not diminished until the inspired oxygen concentration falls below 10 per cent - as a matter of fact, not until it falls to about 5 per cent.

When the "anaerobic metabolic rate" (rate of accumulation of excess lactate in local venous blood) was measured for individual regions of the body in animals breathing a 10 per cent oxygen mixture, some of the tissue regions showed anaerobic metabolism to the extent of 20 to 30 per" cent of their total energy metabolism (Fig. 4), even though there was no appreciable whole body oxygen debt (HuCKabee 1959). HuCKABEE claims that anaerobic energy production is a part of the normal mechanism of energy supply to tissues, and that it is not necessarily indicative of generalized hypoxia. The reverse is also true, i. e., measurement of whole body oxygen debt gives no reliable indication of the adequacy of the rate of oxygen supply to any particular tissue.

It must be concluded that the usual textbook discussion of hypoxia is over-simplified. The intracellular oxygen tension required to maintain a normal $\mathrm{NAD}: \mathrm{NADH}_{2}$ ratio and normal electrical activity of the brain appears to be of the order of $1 \mathrm{~mm} \mathrm{Hg}$, and this is not endangered until the inspired oxygen concentration drops to 5 per cent or lower. How are these facts to be reconciled with the obvious distress experienced by men at altitudes equivalent to much higher oxygen concentrations, and with the regional tissue anaerobic metabolism observed in animals breathing 10 per cent oxygen? The apparent discrepancy between the hypoxic threshold indicated by a change in the NAD : $\mathrm{NADH}_{2}$ ratio and that measured by an increase in excess lactate, if found to be real, suggests a promising line of further study. It may reflect a sequence of adjustments to hypoxia in which increased anaerobic metabolism precedes (and delays) the shift of $\mathrm{NAD}: \mathrm{NADH}_{2}$ from the steady-state ratio. This is consistent with HucKaBEE's belief that anaerobic metabolism is a normal source of energy, at least in some tissues, but it does not explain the increase in anaerobic glycolysis, which is usually attributed to an increased availability of ADP when oxidative phosphorylation is depressed.

How does hypoxia affect the cell? The most immediate consequence, of course, is a decrease in the capacity for the formation of ATP by oxidative phosphorylation, i.e.,

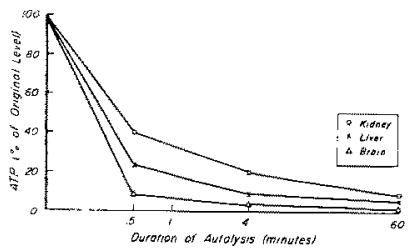

Fig. 5: Rate of change of ATP concentration in kidney, liver and brain of the rat following sudden interruption of blood supply. (From Sanders, HaLE \& MiLLER 1965a, by permission of the American Journal of Physiology)

oxygen has now become a rate-limiting factor, or regulator. Since the reserves of ATP are extremely limited, they are soon exhausted. When the oxygen lack is total (as following decapitation of the animal) the ATP falls to very low levels in a matter of seconds (Fig. 5); the rate of fall is especially rapid in brain (SANDERs, HALE \& MILLER 
1965a). When hypoxia is induced by the breathing of 5 per cent oxygen, however, the picture is quite different (SANDERs, HaIE \& Miller 1965b). While there is a considerable reduction in liver ATP, the reduction is much less in brain, and there is essentially no change in kidney ATP (Table 1). This may reflect, in part, differences in the effect of hypoxia on the blood flow to various organs (for example, in severe hypoxia there is a

Table 1

Effect of hypoxia on tissue ATP concentration. Values are means \pm Standard deviation; number of observations is given in parentheses

\begin{tabular}{|cccc|}
\hline $\begin{array}{c}\text { Duration } \\
\text { of hypoxia } \\
\text { (min) }\end{array}$ & Liver & $\begin{array}{c}\text { ATP Concentration, } \mu \mathrm{M} / \mathrm{g} \text { Tissue } \\
\text { Kidney }\end{array}$ & Brain \\
\hline 0 & $1.74 \pm 0.36(8)$ & $1.13 \pm 0.16(12)$ & $3.59 \pm 0.12(6)$ \\
60 & $1.16 \pm 0.48(6)$ & $1.06 \pm 0.21(6)$ & \\
105 & $1.01 \pm 0.23(5)$ & $1.27 \pm 0.16(5)$ & $2.91 \pm 0.40(5)$ \\
\hline
\end{tabular}

decrease in liver blood flow but an increase in brain blood flow). The surprising maintenance of kidney ATP levels may perhaps be attributed to the fact that kidney blood flow is greatly in excess of the nutritional requirements of the kidney, so that a considerable increase in the extraction of oxygen from the blood can occur at the expense of a relatively small change in the A-V oxygen difference. It is apparent that the organism reacts in a heterogeneous manner to a decrease in its oxygen supply, and that, accordingly, the results of studies on one organ cannot be assumed to apply to other organs.

How does a reduction in the ATP supply of cells affect their various types of activities? Is there a preferential use of the available ATP for activities essential for survival of the cells, at the expense of less essential activities? Quantitative information is meager, although the problem offers no very great technical difficulties. On the assumption that the synthesis of protein for export, though important for the organism, is less so for the cell performing the synthesis, we (Sanders, Hale \& Miller 1965b) studied the rate of incorporation of ${ }^{4} \mathrm{C}$-leucine into protein in the liver, kidney and brain of rats breathing 5 per cent oxygen (Table 2). The rate of incorporation was severely depressed in liver, which synthesizes much protein for export, and less so in brain and kidney, which do nor manufacture protein for export. The experiment was not completely convincing, however, since the greatest decrease in blood flow also occurred in the liver, and this could affect the rate of amino acid incorporation by reducing the amount of the amino acid presented to the cells. It may be significant that the regulation of sodium and water distribution between liver cells and their environment, a matter of vital concern to the cells, was much less severely affected by hypoxia than was the synthesis of protein. Studies on other types of cellular activities, and in a variety of types of cells, are needed for a definitive answer to this important problem.

Many years ago, HARDANE (1919) stated that hypoxia (which he called anoxemia) not only stops the machine, but also wrecks the machinery, and this dictum has been 


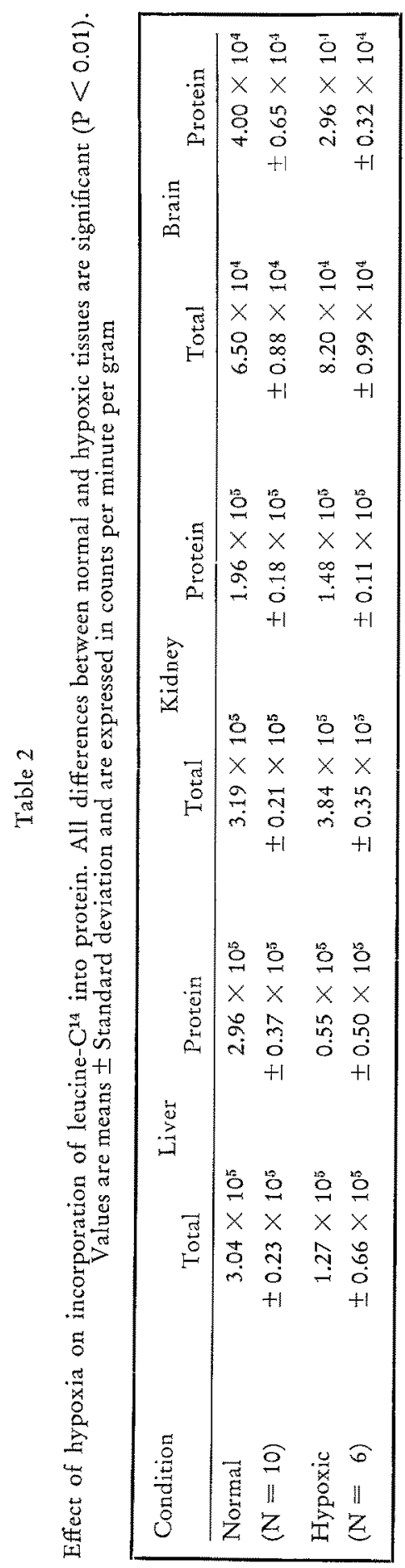


taught to several generations of students. We have attempted (SANDERS, Hale \& Miller $1965 \mathrm{a}$ and b) to define the nature and extent of the damage to the metabolic machinery of the cell by polarographic studies on homogenates of tissues from animals

Table 3

Effect of autolysis on capacity of rat liver for respiration and oxidative phosphorylation. Values are means \pm Standard deviation; ${ }^{1} \mu$ liters $0_{2} / \mathrm{mg}$ wet wt per $\mathrm{hr} ;{ }^{2}$ respiratory control ratio $=\mathrm{ADP}-$ qoz $/$ basal qog

\begin{tabular}{|clccccc|}
\hline $\begin{array}{c}\text { Duration } \\
\text { of } \\
\text { autolysis } \\
\text { (min) }\end{array}$ & Substrate & Basal qo2 & ADP-qo2 & RCR & ADP/O & $N$ \\
\hline 0 & Succinate & $3.12 \pm 0.30$ & $7.96 \pm 0.98$ & $2.55 \pm 0.28$ & $2.05 \pm 0.12$ & 7 \\
30 & Succinate & $3.23 \pm 0.41$ & $7.64 \pm 0.78$ & $2.39 \pm 0.32$ & $2.05 \pm 0.10$ & 5 \\
60 & Succinate & $3.57 \pm 0.33$ & $6.82 \pm 0.36$ & $1.92 \pm 0.16$ & $1.97 \pm 0.11$ & 6 \\
90 & Succinate & $4.52 \pm 0.18$ & $6.21 \pm 0.24$ & $1.37 \pm 0.05$ & $2.01 \pm 0.08$ & 5 \\
0 & a-Ketoglutarate & $1.68 \pm 0.22$ & $3.26 \pm 0.59$ & $1.94 \pm 0.25$ & $3.05 \pm 0.22$ & 7 \\
30 & a-Ketoglutarate & $1.62 \pm 0.10$ & $3.43 \pm 0.21$ & $2.11 \pm 0.05$ & $2.80 \pm 0.16$ & 5 \\
60 & a-Ketoglutarate & $2.01 \pm 0.37$ & $3.22 \pm 0.36$ & $1.61 \pm 0.06$ & $2.81 \pm 0.13$ & 6 \\
90 & a-Ketoglutarate & $2.27 \pm 0.26$ & No stim. & & \\
0 & Glutamate & $1.91 \pm 0.23$ & $4.10 \pm 0.82$ & $2.13 \pm 0.32$ & $2.98 \pm 0.12$ & 7 \\
30 & Glutamate & $1.74 \pm 0.18$ & $3.94 \pm 0.35$ & $2.29 \pm 0.39$ & $2.72 \pm 0.21$ & 5 \\
60 & Glutamate & $2.13 \pm 0.25$ & $3.37 \pm 0.39$ & $1.59 \pm 0.13$ & $2.85 \pm 0.17$ & 6 \\
90 & Glutamate & $2.86 \pm 0.20$ & No stim. & & & 5 \\
\hline
\end{tabular}

Table 4

Effect of autolysis on capacity of rat kidney cortex for respiration and oxidative phosphorylation. Values are means \pm Standard deviation

\begin{tabular}{|cllllll|}
\hline $\begin{array}{c}\text { Duration } \\
\text { of } \\
\text { autolysi } \\
\text { (min) }\end{array}$ & Substrate & Basal qo2 & ADP-q09 & RCR & ADP/O & N \\
\hline 0 & Succinate & $6.59 \pm 0.20$ & $14.20 \pm 0.72$ & $2.16 \pm 0.10$ & $2.05 \pm 0.06$ & 8 \\
30 & Succinate & $5.41 \pm 0.62$ & $9.58 \pm 0.86$ & $1.78 \pm 0.15$ & $2.10 \pm 0.10$ & 5 \\
60 & Succinate & $5.84 \pm 0.57$ & $8.37 \pm 0.71$ & $1.43 \pm 0.03$ & $2.02 \pm 0.06$ & 5 \\
90 & Succinate & $6.37 \pm 0.84$ & No stim. & & & \\
0 & a-Ketoglutarate & $2.72 \pm 0.13$ & $6.96 \pm 0.25$ & $2.57 \pm 0.20$ & $2.97 \pm 0.15$ & 8 \\
30 & -Ketoglutarate & $2.58 \pm 0.16$ & $5.39 \pm 0.19$ & $2.10 \pm 0.19$ & $3.02 \pm 0.13$ & 5 \\
60 & - -Ketoglutarate & $3.00 \pm 0.19$ & $4.64 \pm 0.30$ & $1.55 \pm 0.08$ & $2.89 \pm 0.22$ & 5 \\
90 & a-Ketoglutarate & $3.15 \pm 0.65$ & No stim. & & & \\
0 & Glutamate & $2.88 \pm 0.22$ & $4.92 \pm 0.40$ & $1.72 \pm 0.15$ & $2.94 \pm 0.13$ & 8 \\
30 & Glutamate & $2.60 \pm 0.28$ & $4.22 \pm 0.30$ & $1.63 \pm 0.10$ & $2.96 \pm 0.06$ & 5 \\
60 & Glutamate & $2.98 \pm 0.25$ & $3.94 \pm 0.37$ & $1.32 \pm 0.07$ & $2.90 \pm 0.13$ & 5 \\
90 & Glutamate & $2.87 \pm 0.67$ & No stim. & & & 5 \\
\hline
\end{tabular}

rendered moderately or severely hypoxic. The results indicate that the machinery, or at least the component parts, is very rugged. Complete ischemia, lasting as long as 60 minutes, had little effect on the subsequent capacity of homogenates of the liver, kidney and brain to oxidize substrates, and there was no uncoupling of oxidative phosphorylation (considered to be a sensitive indicator of damage to metabolic machin- 
Role of oxygen in metabolic regulation

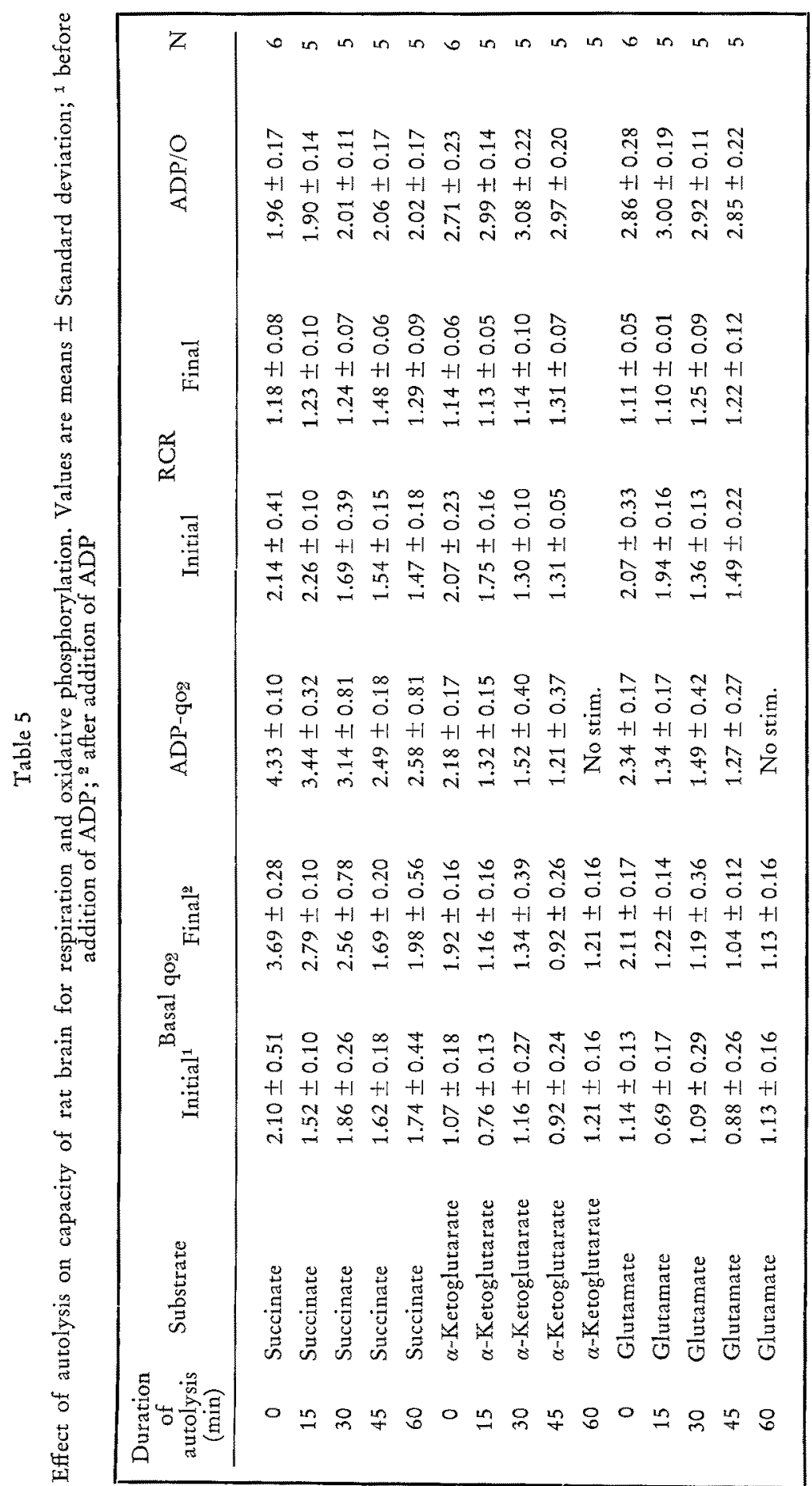


ery) (Tables 3, 4 and 5). The only significant metabolic alteration attributable to the effects of hypoxia was a decrease in mitochondrial respiratory control (stimulation of oxygen consumption by the addition of ADP to the system), but even this property was well-preserved for at least 45 minutes. Pre-treatment of the animals with an intracellular buffer (THAM) greatly delayed the onset of hypoxic damage to the metabolic machinery, supporting the concept that increased intracellular acidity is a major factor in hypoxic damage (Hall \& Miller 1965). When animals breathed a 5 per cent oxygen mixture for periods of almost two hours, there was no adverse effect on the subsequent capacity of homogenates of the tissues to carry out oxidative phosphorylation and to show ADP-stimulation of respiration (Table 6).

Table 6

Effect of hypoxia on capacity for respiration and oxidative phosphorylation. Values are means \pm Standard deviation; 1 liters $\mathrm{O}_{2} / \mathrm{mg}$ wet wt per hr; ${ }^{2}$ respiratory control ratio-ADP-qog/ basal qog

\begin{tabular}{|c|c|c|c|c|c|c|}
\hline $\begin{array}{l}\text { Duration } \\
\text { of } \\
\text { hypoxia } \\
\text { (min) }\end{array}$ & Substrate & Basal qo2 ${ }^{1}$ & ADP-qo. ${ }^{1}$ & $\mathrm{RCR}^{2}$ & $\mathrm{ADP} / \mathrm{O}$ & $\mathbb{N}$ \\
\hline \multicolumn{7}{|c|}{ Liver } \\
\hline 0 & Succinate & $3.12 \pm 0.30$ & $7.96 \pm 0.98$ & $2.55 \pm 0.28$ & $2.05 \pm 0.12$ & 7 \\
\hline 105 & Succinate & $3.26 \pm 0.40$ & $9.54 \pm 1.25$ & $2.98 \pm 0.60$ & $1.95 \pm 0.07$ & 5 \\
\hline 0 & $\alpha$-Ketoglutarate & $1.68 \pm 0.22$ & $3.26 \pm 0.59$ & $1.94 \pm 0.25$ & $3.05 \pm 0.22$ & 7 \\
\hline 105 & $\alpha$-Ketoglutarate & $1.54 \pm 0.14$ & $4.74 \pm 0.77$ & $3.06 \pm 0.41$ & $2.80 \pm 0.16$ & 5 \\
\hline 0 & Glutamate & $1.91 \pm 0.23$ & $4.10 \pm 0.82$ & $2.13 \pm 0.32$ & $2.98 \pm 0.12$ & 7 \\
\hline 105 & Glutamate & $1.63 \pm 0.17$ & $5.32 \pm 0.69$ & $3.27 \pm 0.34$ & $2.74 \pm 0.09$ & 5 \\
\hline \multicolumn{7}{|c|}{ Kidney } \\
\hline 105 & Succinate & $6.59 \pm 1.32$ & $12.70 \pm 1.81$ & $1.95 \pm 0.13$ & $2.00 \pm 0.17$ & 5 \\
\hline & $a$-Ketoglutarate & $2.72 \pm 0.13$ & $6.96 \pm 0.25$ & $2.57 \pm 0.20$ & $2.97 \pm 0.15$ & 8 \\
\hline 105 & $\alpha$-Ketoglutarate & $2.73 \pm 0.45$ & $5.57 \pm 1.20$ & $2.03 \pm 0.13$ & $2.94 \pm 0.15$ & 5 \\
\hline 0 & Glutamate & $2.88 \pm 0.22$ & $4.92 \pm 0.40$ & $1.72 \pm 0.15$ & $2.94 \pm 0.13$ & 8 \\
\hline 105 & Glutamate & $2.75 \pm 0.49$ & $4.51 \pm 1.00$ & $1.63 \pm 0.11$ & $2.93 \pm 0.22$ & 5 \\
\hline \multicolumn{7}{|c|}{ Brain } \\
\hline 0 & Succinate & $2.10 \pm 0.51$ & $4.33 \pm 0.10$ & $2.14 \pm 0.41$ & $1.96 \pm 0.17$ & 6 \\
\hline 105 & Succinate & $2.05 \pm 0.10$ & $4.37 \pm 0.24$ & $2.14 \pm 0.15$ & $1.78 \pm 0.07$ & 5 \\
\hline 0 & $a$-Ketoglutarate & $1.07 \pm 0.18$ & $2.18 \pm 0.17$ & $2.07 \pm 0.23$ & $2.71 \pm 0.23$ & 6 \\
\hline 105 & a-Ketoglutarate & $0.92 \pm 0.09$ & $1.95 \pm 0.11$ & $2.13 \pm 0.16$ & $2.75 \pm 0.18$ & 5 \\
\hline 0 & Glutamate & $1.14 \pm 0.13$ & $2.34 \pm 0.17$ & $2.07 \pm 0.33$ & $2.86 \pm 0.28$ & 6 \\
\hline 105 & Glutamate & $0.88 \pm 0.18$ & $1.82 \pm 0.22$ & $2.09 \pm 0.32$ & $2.61 \pm 0.10$ & 5 \\
\hline
\end{tabular}

In summary, hypoxia of moderate degree, induced by the breathing of a 10 per cent oxygen mixture, has little or no effect on the respiratory metabolism of cells, despite the often striking systemic responses. When the inspired oxygen concentration drops to 5 per cent or lower, there is a progressive failure of oxidative phosphorylation, more marked in some organs than in others, a fall in the ATP concentration in some (but not all) tissues, and a depression of protein synthesis, especially in the liver. When the hypoxia is still more severe, there is a failure of active transport of amino acids and electrolytes. The metabolic machinery, however, remains more or less intact, except after the prolonged complete absence of oxygen when there occurs a progressive 
loss of mitochondrial respiratory control, i. e. the capacity of the mitochondria to adjust the level of their metabolism to the demands of the normal ADP-feedback regulator.

\section{ADAPTATION TO CHRONIC HYPOXIA}

It is a familiar fact that the distress experienced on first going to high altitude gradually diminishes as the exposure continues, and that the natives of high altitude regions are capable of far greater activity than are newly-arrived or even "acclimatized" sea-level natives. This indicates that adaptive and perhaps selective factors are involved. A similar adjustment to hypoxia apparently occurs in patients with cyanotic heart disease. Goldschmod \& Light (1925) described a case of patent ductus arteriosus in which the arterial oxygen saturation was only 45 per cent, which corresponds to the breathing of air containing only 3.5 per cent oxygen, or to an altitude of 42,000 feet. Under such conditions the cells must have functioned at a level of oxygen tension scarcely compatible with life unless very successful acclimatization had been achieved.

The nature of the process of acclimatization to chronic hypoxia is incompletely understood despite intensive study. We do not know precisely what is accomplished by acclimatization, nor how to measure acclimatization in objective terms. Since the ultimate effect of hypoxia is to reduce the capacity for the synthesis of ATP, by making oxygen a metabolic rate-limiter, acclimatization ought to reverse this change. This might be brought about either by increasing the delivery of oxygen to the cells (systemic adaptation) or by making it possible for the cells to form ATP despite the lowered intracellular oxygen tension (cellular adaptation). When rats are made to breathe a low oxygen mixture ( 5 per cent $\mathrm{O}_{2}$ to 95 per cent $\mathrm{N}_{2}$ ), there is a reduction in the ATP content of brain, heart and liver. If altitude-acclimatized animals are used, it would be expected that they would maintain a higher ATP level during the breathing of the low oxygen mixture than would non-acclimatized animals and that the margin of superiority would provide a quantitative measure of the degree of acclimatization. Unfortunately, in preliminary experiments in our laboratory, altitudeacclimatized rats have shown no superiority over non-acclimatized animals. It may be that the superiority of altitude-acclimatized animals is manifested only under conditions of combined hypoxia and activity. For example, HALL \& BARKER (1954) found that altitude-acclimatized mice had an increased running time to exhaustion in an atmosphere of 6.9 per cent oxygen. It might be instructive to compare work performance, tissue oxygen tensions and tissue ATP concentrations in acclimatized and non-acclimatized animals when both groups are forced to maximal activity under hypoxic conditions. At the present time, the only objective estimation of altitude acclimatization is based on the increased duration or proficiency of performance of some activity under hypoxic conditions. This should be emphasized because it is often assumed that certain measurable changes associated with acclimatization actually constitute the state of acclimatization. An example is the polycythemia, which usually occurs in persons who go to high altitude. This may or may not be an entirely benefi- 
cial response - opinion is divided - but it is not acclimatization, which can be defined as the increased capacity of cells to function adequately when their oxygen supply is reduced. Nor are the cardiovascular and respiratory responses to hypoxia in themselves a measure of acclimatization, since they occur in both acclimatized and nonacclimatized subjects (though perhaps with greater efficiency in the former).

Do cells show adaptive changes to hypoxia? The literature on this subject is extensive and conflicting. Increases in the activities of the glycolytic and oxidative enzymes, as well as in the members of the electron transfer chain, in response to chronic hypoxia, have been both claimed and denied. There is little direct evidence that the enzyme changes which have been reported actually increase the utilization of the available oxygen under conditions of oxygen deficiency. Under normal conditions, oxygen is present in excess and hence is not a factor in the regulation of metabolic rate. When the intracellular oxygen tension is extremely low (probably less than $0.05 \mathrm{~mm} \mathrm{Hg}$ ), cytochrome $a_{3}$ should be almost completely reduced, and the rate of oxygen consumption would depend mainly on the concentration of oxygen. At intermediate levels, the rate of oxygen consumption would depend on the product of the concentrations of oxygen and of reduced cytochrome $a_{3}$. This is the range of practical importance, and any adjustment which increases the supply of reduced cytochrome $a_{3}$ could increase the utilization of oxygen. Since there is no identifiable rate-limiting factor in the respiratory chain (JöвsIs 1964), an increase in any of the components might increase the overall rate of electron transfer to oxygen. Also, since the peak operation of the respiratory chain depends on the supply of $\mathrm{NADH}_{2}$, increases in rate-limiting components of the Krebs cycle might be expected to be beneficial, especially since there is some evidence that the respiratory chain units are present in relative excess to the substrate dehydrogenases (JöBsis 1964). Adaptive changes in the glycolytic system might involve increases in individual components which, if normally rate-limiting, would result in the formation of larger amounts of pyruvate. Another adaptive change might involve a shift in the relative proportions of the $\mathrm{M}$ and $\mathrm{H}$ forms of lactic dehydrogenase in favor of the $M$ form, which is not inhibited by the high concentrations of pyruvate made available by the increased rate of glycolysis. Since the reverse change occurs in some tissues shortly before or after birth (CAHN et al. 1962), this is not an unreasonable suggestion. Negative results have been reported for the frog (GRAINGER \& KUnz 1966), but the frog has a great capacity for anaerobic metabolism, and therefore might not show adaptive changes to hypoxia to the degree characteristic of higher animals.

Cellular adaptation to hypoxia might involve not only increased capacity to form ATP at low intracellular oxygen tension but also a preferential use of the available supply of ATP for the activities most essential for survival, at the expense of activities having less immediate survival value. This is largely hypothetical, but it perhaps has its counterpart in the decrease in synthesis of protein for export in the acutely hypoxic liver (SANDers, Hare \& MrLler 1965b). If this should prove to be a factor in the cellular adjustment to hypoxia, the mechanism which permits the cell to select the activities to which it will devote its meager supply of energy will remain a fascinating problem to be solved. 


\section{SUMMARY}

1. Under ordinary conditions the rate of energy metabolism in cells is governed by the ADP-feedback system, since the other reactants (inorganic phosphate, substrate, oxygen, enzymes and co-factors) are present in relative excess.

2. When the supply of oxygen is severely limited, it may assume the characteristics of a rate-limiter, and the pattern as well as the rate of metabolism may be altered.

3. The quantitative estimation of the severity of hypoxia is a more difficult problem than is generally realized. The available approaches include: direct measurement of tissue (perhaps intracellular) oxygen tension with micro-electrodes, measurement of the oxidation-reduction status of cells in terms of the ratios of oxidized and reduced forms of electron carrier components (e. g. NAD : $\mathrm{NADH}_{2}$ ), measurement of the concentrations of high energy compounds in the tissues, and measurement of the "excess lactate" concentration of tissues. The results of these various methods are not always in agreement, and the cause of this lack of agreement is an important problem to be solved.

4. Other important unsolved problems in this field are the relation between intracellular oxygen tension and the partition of ATP-formation between aerobic and anaerobic pathways, and the possible conservation of limited supplies of ATP by its selective utilization for those functions essential for cell survival.

5. Adaptation to chronic hypoxia may involve systemic adjustments which increase the delivery of oxygen to the cells, and cellular adjustments which enable the cells to survive a decrease in their oxygen supply. The occurrence of the systemic adjustments is well established, but the occurrence of cellular adjustments is controversial.

6. It may be concluded that oxygen tension becomes a metabolic regulator only when the intracellular oxygen tension falls to very low levels indeed.

7. The responses of the cells to this condition of severe oxygen deficiency may include: (a) adaptive enzyme changes which permit more efficient utilization of the available oxygen, (b) increased contribution of anaerobic metabolism, and (c) selective utilization of the available energy supply for those functions which are most essential for the survival of the cells.

\section{ACKNOWLEDGEMENT}

The work of the author included in this review was supported by the U.S. Army Research and Development Command, Department of the Army, under Research Contract DA-49-193MD-2371.

\section{LITERATURE CITED}

Cahn, R. D., Kaplan, N. O., Levine, L. \& Z Zlling, E., 1962. Nature and development of lactic dehydrogenases. Science Wasbington, D. C. 136, 962-969.

Cater, D. B. \& Silver, I. A., 1961. Microelectrodes and electrodes used in biology. In: Reference electrodes. Ed. by D. J. G. Ives \& G. J. Janz. Acad. pr. New York, 503-515.

Chance, B., Schoener, B. \& Schindler, F., 1964. The intracellular oxidation-reduction state. In: Oxygen in the animal organism. Ed. by F. Dickens \& E. Neil. MacMillan, New York, $367-388$. 
- \& Wrluams, G. R., 1956. The respiratory chain and oxidative phosphorylation, Adv. Enzymol. 17, 65-134.

Goldschmidt, S. \& IIGHT, A. B., 1925. Methods of obtaining from veins blood similar to arterial in gaseous content. J. biol. Chem. 64, 53-58.

Grainger, J. N. R. \& Kunz, Y., 1966. Changes in the isoenzymes of lactic and malic dehydrogenase during the development of the frog Rana temporaria. Helgoländer wiss. Meeresunters. 14, 335-342.

Haldane, J. S., 1919. Symptoms, causes and prevention of anoxaemia (insufficient supply of oxygen to the tissues) and the value of oxygen in its treatment. Br. med. J. 2, 65-71.

Hall, F. G. 8. Barker, J., 1954. Performance of acclimatized mice at altitude. Proc. Soc. exp. Biol. Med. 86, 165-167.

HaLl, I. H. 8 MrLeR, A. T., Jr., 1965 (Unpublished observations).

HucKABEE, W. E., 1958a. Relationships of pyruvate and lactate during anaerobic metabolism. 1. Effects of infusion of pyruvate or glucose and of hyperventilation. I. clin. Invest. 37, 255-263.

- 1958b. Relationships of pyruvate and lactate during anaerobic metabolism. 3. Effect of breathing low-oxygen gases. J. clin. Invest. 37, 264-271.

- 1959. Relationship of pyruvate and lactate during anaerobic metabolism. 4. Local tissue components of total body $\mathrm{O}_{2}$-debt. Am. J. Physiol. 196, 253-260.

Jöвsıs, F. F., 1964. Basic processes in cellular respiration. In: Handbook of physiology. Sect. 3, Vol. 1, Ed. by W. O. Fenn \& H. Rahn. Am. Physiol. Soc. Washington, D. C., 63-124.

Longmutr, I. S., 1964. The oxygen electrode. In: Oxygen in the animal organism. Ed. by F. Dickens \& E. Neil. MacMillan, New York, 219-237.

Sanders, A. P., HAle, D. M. \& Mrller, A. T., Jr., 1965a. Respiratory metabolism in rat tissues atter autolysis in situ. Am. J. Physiol. 209, 438-442.

- - 1965b. Some effects of hypoxia on respiratory metabolism and protein synthesis in rat tissues. Am. J. Physiol. 209, 443-446.

SILVER, I. A., 1965 (Personal communication).

WINZLER, R. J., 1941. The respiration of bakers' yeast at low oxygen tension. J. cell. comp. Physiol. 17, 263-276.

\section{Discussion following the paper by MnLER}

Voss: Der geringe Abfall des ATP in der Niere unter Hypoxie ist für mich überraschend, da die Niere - wie das Gehirn - praktisch keinen Kreatinphosphatpuffer enthält, der einen gewissen Schutz gegen die Hypoxie darstellt. Deshalb ist die maximale Funktionszeit der Niere und des Gehirns ja so kurz. Ein Sauerstoffmangel müßte demnach einen größeren Anfall des ATP in der Niere bewirken.

MrLLER: There is nothing really surprising about the lack of significant decrease in kidney ATP in animals breathing $5 \%$ oxygen and $95 \%$ nitrogen since (1) the blood flow to the kidney is normally greatly in excess of nutritional requirements, so that greater extraction of oxygen from the blood in hypoxia might result from increase in the A-V oxygen difference, and (2) $5 \%$ oxygen is just about the transition point for increased deviation of DPN: DPNH from the steady-state level in CHANCE's experiments.

MaRMasse: (1) I wonder if many data about redox potentials of cell suspensions should not be re-evaluated in the light of what Dr. Muleer just told us about hypoxia. (2) A few years ago there was a lot of talk about a possible relation between schizophrenia and the value of the ratio lactate/pyruvate.

Mrles: I have no direct experience with the changes in the lactate/pyruvate ratio in schizophrenia. Since pyruvate metabolism is disturbed in some disorders of the nervous system, I would suspect that changes in lactate might be secondary to changes in pyruvate, but this could readily be verified by comparing the lactate level measured with that predicted from the measured change in pyruvate. It seems to me that hypoxia is a less likely factor. 